\title{
MEMAHAMI FILSAFAT PANCASILA SEBAGAI PANDANGAN HIDUP IDEOLOGI \& DASAR NEGARA
}

\author{
Dany Try Hutama Hutabarat ${ }^{1}$, Roffi Rivaldo Arya Sutta ${ }^{2}$, Wahyu Habib Wardana ${ }^{3}$, Zahra \\ Nur Fadila ${ }^{4}$, Prety Sapahira ${ }^{5}$, Rani Tanjung ${ }^{6}$ \\ ${ }^{1-6}$ Jurusan Ekonomi Pembangunan, Fakultas Ekonomi, Universitas Asahan \\ E-mail: ${ }^{1)}$ danytryhutamahutabarat@gmail.com, ${ }^{2)}$ rovirevaldo@gmail.com, \\ ${ }^{3)}$ habibw465@gmail.com, ${ }^{4)}$ shradila@gmail.com, ${ }^{5}$ pretisapahiraa@gmail.com, \\ ${ }^{6}$ ranitanjung05@gmail.com
}

\begin{abstract}
This study aims to understand the philosophy of Pancasila as a view of life, ideology, and the basis of the state. The influence of globalization is unavoidable. Globalization makes all countries into unlimited countries. Pancasila is needed to filter the influence of globalization. In today's era, the meaning of Pancasila has been forgotten by some people in Indonesia. The process of formulating Pancasila even though it was a very long process. Pancasila is a guide in the life of the nation and state. Therefore, Pancasila is referred to as a view of life, ideology and the basis of the state. The structure of Pancasila itself shows a series of tiers in which each precept has its own place in the unity, so that it cannot be changed anymore. Pancasila is the basis for regulating the administration of a country's administration in the fields of ideology, politics, economy, socio-culture, defense and state security.
\end{abstract}

Keywords: Pancasila, View of life, Basic State

\section{PENDAHULUAN}

Berdasarkan falsafah Pancasila, manusia adalah makhluk ciptaan Tuhan yang mempunyai naluri, akhlak, daya pikir, dan sadar akan keberadaannya yang serba terhubung dengan sesamanya, lingkungannya, alam semesta, dan penciptanya (Arum \& Dewi, 2021; Nurizka \& Rahim, 2020). Kesadaran ini menumbuhkan cipta, karsa, dan karya untuk mempertahankan eksistensi dan kelangsungan hidupnya dari generasi ke generasi (Suradinata, 2001).

Lambang Pancasila adalah seekor burung garuda yang memiliki makna kekuatan dengan warna emas sebagai simbol kemuliaan. Pancasila memiliki beberapa kedudukan dalam kehidupan bernegara, yaitu :

a) Sebagai Jiwa Bangsa

b) Sebagai Ciri dan Pribadi Bangsa

c) Sebagai Pedoman Hidup Bangsa

d) Sebagai Dasar Negara

e) Sebagai Sumber dari segala Hukum

f) Sebagai perjanjian yang luhur ketika negara Indonesia didirikan

g) Sebagai Tujuan dan cita - cita bangsa 
Pancasila memiliki nilai sejarah yang tinggi, karena proses pembentukkannya melalui proses yang sangat panjang. Pancasila sebagai pandangan hidup bangsa Indonesia memiliki fungsi sebagai pegangan atau acuan bagi manusia Indonesia dalam bersikap dan bertingkah laku, berkaitan dengan sistem nilai, tentang baik dan buruk, adil, jujur, bohong, dan sebagainya (Hadiwijono, 2016). Setiap perbuatan yang dilakukan sehari - hari harus sesuai dengan dengan nilai - nilai Pancasila. Nilai - nilai Pancasila telah melekat erat pada masyarakat Indonesia. Setiap manusia memiliki pandangan hidup yang berbeda dalam menentukan masa depannya (Asmaroini, 2017). Namun walaupun berbeda, pandangan hidup masyarakat Indonesia harus sesuai dengan Pancasila. Makna Pancasila sebagai pandangan hidup bermakna nilai - nilai ketuhanan, kemanusiaan, persatuan, kerakyatan, dan keadilan. Pancasila diterapkan pada kehidupan berbangsa dan bernegara.

Pancasila adalah dasar negara. Semua hukum yang berlaku di Indonesia bersumber dari Pancasila. Sehingga, Pancasila digunakan sebagai dasar untuk mengatur pemerintahan dan penyelenggaraan negara. Oleh karena itu nilai - nilai pancasila harus tetap dilestarikan demi kelangsungan hidup bangsa dan negara Indonesia.

Pancasila sebagai ideologi, istilah ideologi berasal dari kata 'idea' berarti gagasan, konsep, pengertian dasar, cita-cita, dan 'logos' berarti ilmu. Kata idea sendiri berasal dari bahasa Yunani 'eidos' yang artinya bentuk. Selanjutnya ada kata 'idein' yang artinya melihat. Dengan demikian secara harfiah ideologi berarti ilmu pengertian-pengertian dasar, cita-cita yang bersifat tetap yang harus dicapai (Kirom, 2015). Pancasila sebagai ideologi negara yang dikaitkan dalam Pembangunan Nasional yaitu mewujudkan masyarakat adil dan makmur baik secara material maupun spritual.

Kelangsungan hidup negara dan bangsa Indonesia di era globlalisasi, mengharuskan kita untuk melestarikan nilai-nilai Pancasila, agar generasi penerus bangsa tetap dapat mengamalkannya sepanjang masa. Mengingat Pancasila adalah dasar Negara, maka mengamalkan dan mengamankan Pancasila sebagai dasar negara mempunyai sifat imperatif/ memaksa artinya setiap warga negara Indonesia harus tunduk/taat kepadanya.

\section{METODE PENELITIAN}

Metode dalam penulisan adalah dengan metode deskriptif-analitis serta mengggunakan metode hermeneutic (Tamrin, 2017), kemudian dilakukan pencarian data-data yang paling relevan dan utama terkait dengan pancasila sebagai pandangan hidup, ideologi, dan dasar negara, selanjutnya dilakukan analisis yang lebih tajam sehingga menghasilkan gagasan atau ide yang kreatif.

\section{TEMUAN DAN PEMBAHASAN}

\subsection{Pancasila sebagai Pandangan Hidup}




\section{JOURNAL OF HUMANITIES, SOCIAL SCIENCES AND BUSINESS (JHSSB) \\ VOLUME 1 ISSUE 2 (2022)}

Pancasila adalah dasar negara yang digunakan sebagai pandangan hidup bangsa Indonesia. Karena Pancasila disebut sebagai pandangan hidup, Pancasila bermakna sebagai jiwa bangsa, kepribadian bangsa, dan sumber hukum negara.

Pedoman dan perilaku sikap masyarakat harus selalu menjiwai nilai - nilai luhur Pancasila. Nilai - nilai tersebut sesuai dengan kelima bunyi pancasila. Sila pertama yang berbunyi "Ketuhanan Yang Maha Esa", dalam artian masyarakat Indonesia harus mengakui adanya Tuhan dan melakukan kewajiban agama serta saling menghormati keyakinan masing - masing. Sila Kedua berbunyi "Kemanusiaan Yang Adil dan Beradab", sila ini bermakna bahwa masyarakat Indonesia harus mengakui kedudukan manusia yang sama dan saling menghormati hak dan kewajiban setiap orang. Sila Ketiga berbunyi "Persatuan Indonesia", maknanya yaitu masyarakat Indonesia harus mengutamakan persatuan dan kesatuan bangsa daripada kepentingan pribadi dan kelompok. Sila Keempat berbunyi "Kerakyatan Yang dipimpin Oleh Khidmat Kebijaksanaan dalam Permusyawaratan/Perwakilan”, maknanya yaitu masyarakat Indonesia harus mengutamakan musyawarah untuk menjalankan negara yang demokrasi. Sila Kelima berbunyi “ Keadilan Sosial bagi Seluruh Rakyat Indonesia”, artinya masyarakat Indonesia memiliki tujuan yang sama, yaitu mewujudkan masyarakat yang adil dan makmur.

Jika Pancasila tidak diterapkan dalam kehidupan sehari - hari, maka bangsa Indonesia akan mengalami masalah dan konflik yang besar. Apabila sila pertama tidak diterapkan dalam kehidupan sehari - hari maka akan terjadi konflik antar masyarakat yang berbeda keyakinan/agama. Jadi dapat disimpulkan bahwa ada empat hal yang dapat terjadi jika nilai Pancasila tidak diterapkan dalam kehidupan sehari - hari, yaitu :

a) Kehidupan akan dipenuhi konflik dan kondisi masyarakat yang tidak rukun

b) Menimbulkan pelanggaran hak dan kewajiban

c) Menimbulkan rasa tidak aman dan nyaman

d) Kondisi masyarakat yang tidak tertib

Sila dari Pancasila merupakan suatu kesatuan yang mengandung nilai - nilai luhur bagi negara Indonesia. Setiap sila saling berkaitan satu dengan yang lain. Kita harus melaksanakan dan mengamalkan nilai - nilai Pancasila dalam berbagai aspek kehidupan. Pada zaman sekarang pandangan hidup bangsa dan pandangan hidup masyarakat mempunyai timbal balik (Tilasanti \& Dewantara, 2019). Pandangan hidup pancasila yang Bhineka Tunggal Ika itu harus merupakan asas pemersatu bangsa, sehingga keanekaragaman itu tetap dapat dilestarikan.

Pancasila bertujuan untuk menjaga kelangsungan dan kelestarian bangsa dan negara. Tujuan negara yang dimaksud anatara lain :

a) Memajukan kesejahteraan umum

b) Mencerdaskan kehidupan bangsa

c) Ikut melaksanakan ketertiban dunia berdasarkan kemerdekaan, perdamaian abadi, dan keadilan sosial. 
Fungsi Pancasila sebagai Pandangan Hidup :

a) Pancasila menjadi petunjuk untuk menyelesaikan berbagai masalah.

b) Pancasila menjadi rujukan untuk menyelesaikan persoalan sosial, budaya, ekonomi, dan politik.

c) Pancasila menjadi acuan bagi warga Indonesia untuk membangun diri nya sendiri sesuai dengan cita - cita bangsa.

d) Pancasila menjadi alat pemersatu warga Indonesia dengan segala keberagaman bahasa, agama, budaya, dan lain sebagainya

\subsection{Pancasila sebagai Ideologi}

Ideologi berasal dari bahasa Yunani yang diambil dari 2 kata, yaitu Idea dan Logos. Idea berarti ide, gagasan, buah pikir, konsep. Sedangkan Logos artinya hasil pemikiran. Jadi, Ideologi adalah kumpulan gagasan - gagasan, ide - ide, keyakinan - keyakinan yang menyeluruh dan sistematis, yang menyangkut berbagai bidang kehidupan manusia (Putri \& Gischa, 2021). Ideologi juga dapat digunakan sebagai tanda pengenal dari sebuah bangsa. Ideologi sebagai identitas bangsa terlihat dari ideologi Pancasila yang dimiliki. Ideologi juga memiliki peran dalam masyarakat yaitu sebagai alat dalam pencegahan terjadinya berbagai konflik dalam masyarakat dan sebagai pemersatu bangsa, sehingga masyarakat dapat hidup aman dan damai

Pancasila diangkat dari nilai adat istiadat, nilai kebudayaan, dan nilai religius yang terdapat dalam pandangan hidup masyarakat Indonesia sebelum membentuk negara. Pancasila sebagai ideologi negara bertujuan sebagai sarana pemersatu masyarakat dan pengaruh motivasi bangsa untuk menggapai cita - cita bangsa dan negara. Pancasila sebagai ideologi negara secara lebih luas adalah untuk terwujudnya kehidupan yang menjunjung tinggi ketuhanan, nilai kemanusiaan, pemersatuan, kerakyatan, dan keadilan.

Peranan Pancasila sebagai Ideologi negara adalah memberi bimbingan kepada rakyat Indonesia dalam bersikap dan bertingkah laku (Zulfikar, 2021). Nilai - nilai yang terkandung dalam pancasila dijadikan patokan aturan berbangsa dan bernegara. Apabila masyarakat melanggar aturan Pancasila sebagai Ideologi negara dilanggar, maka masyarakat akan mendapat hukuman berupa sanksi moral dan sosial.

Makna Pancasila sebagai Ideologi negara yaitu :

a) Nilai - nilai yang terkandung dalam Pancasila dijadikan acuan dalam mencapai citacita bangsa dan negara

b) Nilai - nilai yang ada di dalam Pancasila adalah nilai yang berupa kesepakatan bersama, dan menjadi sarana pemersatu bangsa dan negara.

Mewujudkan Pancasila sebagai cita - cita bangsa, berarti sekaligus menciptkan bangsa yang taat beragama, berperilaku kemanusiaan, demokratis, penuh persatuan, adil serta sejahtera. 


\section{JOURNAL OF HUMANITIES, SOCIAL SCIENCES AND BUSINESS \\ (JHSSB) \\ VOLUME 1 ISSUE 2 (2022)}

\subsection{Pancasila adalah Dasar Negara}

Empat tokoh yang mengusulkan pancasila digunakan sebagai dasar negara, tokoh tokoh tersebut adalah:

1. Mohammad Yamin

2. Dr. Soepomo

3. Ir. Soekarno

Pancasila menjadi dasar negara Indonesia, artinya Pancasila digunakan untuk mengatur pemerintahan dan penyelenggaraan negara. Pancasila juga berfungsi sebagai dasar hukum, baik tertulis maupun tidak tertulis (Camelia, 2021). Makna Pancasila sebagai dasar negara sifatnya tetap, kuat, dan tidak dapat diubah oleh siapa pun. Seluruh peraturan perundang undangan yang berlaku di Indonesia harus bersumber dari Pancasila."Sumber hukum dasar nasional adalah Pancasila sebagaimana yang tertulis dalam Pembukaan Undang - Undang Dasar 1945, yaitu Ketuhanan Yang Maha Esa, Kemanusiaan Yang Adil dan Beradab, Persatuan Indonesia, dan Kerakyatan yang dipimpin oleh khidmat kebijaksanaa dalam permusyawaratan/perwakilan, serta dengan mewujudkan suatu keadilan sosial bagi seluruh Rakyat Indonesia". Kelima sila Pancasila menjelaskan tujuan negara Indonesia berdiri. Pancasila sebagai dasar negara memiliki peran penting bagi kehidupan berbangsa dan bernegara.

Pancasila adalah dasar Negara, maka mengamalkan dan mengamankan Pancasila sebagai dasar negara mempunyai sifat imperatif/ memaksa artinya setiap warga negara Indonesia harus tunduk/taat kepadanya.

Dari pembahasan di atas Pancasila memiliki banyak arti untuk bangsa Indonesia. Pancasila sebagai pandangan hidup, dalam artian setiap perbuatan sehari - hari harus sesuai dengan nilai - nilai Pancasila. Kita sebagai bangsa Indonesia harus melestarikan dan mengamalkan nilai - nilai dari Pancasila. Nilai - nilai Pancasila merupakan satu kesatuan yang tidak dapat dipisahkan antara satu dengan lainnya (Adha \& Susanto, 2020; Widodo, 2015). Pancasila sebagai Ideologi negara, maknanya Pancasila sebagai sarana pemersatu masyarakat dan pengaruh motivasi bangsa untuk menggapai cita - cita bangsa dan negara (Octavian, 2018). Pancasila sebagai ideologi negara secara lebih luas adalah untuk terwujudnya kehidupan yang menjunjung tinggi ketuhanan, nilai kemanusiaan, pemersatuan, kerakyatan, dan keadilan. Pancasila sebagai Dasar Negara, maksud disini adalah Pancasila digunakan untuk mengatur pemerintahan dan penyelenggaraan negara.

Tujuan Pancasila sebagai dasar negara ialah:

a) Membentuk suatu pemerintah Negara Indonesia yang melindungi segenap bangsa Indonesia dan seluruh tumpah darah Indonesia.

b) Memajukan kesejahteraan umum.

c) Mencerdaskan kehidupan bangsa. 
d) Ikut melaksanakan ketertiban dunia yang berdasarkan kemerdekaan perdamaian abadi dan keadilan sosial.

Pancasila diambil dari adat istiadat, nilai - nilai kebudayaan, dan nilai religi yang terdapat dalam pandangan hidup masyarakat.Pancasila mempunyai beberapa kedudukan dalam berbangsa dan bernegara (Sukmalia \& Dewi, 2021). Kedudukan itu ialah Pancasila sebagai jiwa bangsa Indonesia, Pancasila sebagai kepribadian bangsa Indonesia, dan Pancasila sebagai pandangan hidup bangsa.

Pengamalan Pancasila di era globalisai sangat memprihatinkan. Untuk itu perlu kesadaran dari diri sendiri.Pengaruh Globalilasi sangat kuat bagi bangsa Indonesia, kita sebagai generasi penerus bangsa tidak bisa menolak arus globalisasi yang masuk ke dalam negara kita. Namun kita harus mengamalkan nilai - nilai Pancasila dalam kehidupan sehari hari. Tujuan kita mengamalkan nilai - nilai Pancasila yaitu agar kita dapat memfilter pengaruh globalisasi yang terjadi. Nilai yang terkandung dalam sila-sila Pancasila, yang meliputi nilai Ketuhanan, kemanusiaan, persatuan, kerakyatan dan keadilan Jika kita tidak menerapkan nilai - nilai Pancasila dalam kehidupan sehari - hari, maka kehidupan kita akan dipenuhi berbagai masalah dan hidup menjadi tidak aman dan nyaman. Tidak dapat dibayangkan jika nilai Pancasila tidak kita terapkan dalam kehidupan ini. Maka dari itu, Pancasila memiliki sifat imperatif/memaksa artinya warga negara Indonesia harus mematuhi dan patuh/taat terhadap Pancasila. Fungsi Pancasila dalam kehidupan sangat penting, maka sudah seharusnya Pancasila dipahami dan diterapkan oleh warga negara Indonesia.

Dengan demikian, Pancasila sebagai filsafat hidup bangsa harus menjadi petunjuk dan pedoman dalam menjalani kehidupan sehari hari. Kita harus mengamalkan nilai - nilai Pancasila dengan sepenuh hati dan tanggung jawab.

\section{KESIMPULAN}

Dari pembahasan di atas Pancasila memiliki banyak arti untuk bangsa Indonesia. Pancasila sebagai pandangan hidup, dalam artian setiap perbuatan sehari - hari harus sesuai dengan nilai - nilai Pancasila. Nilai - nilai Pancasila merupakan satu kesatuan yang tidak dapat dipisahkan antara satu dengan lainnya. Pancasila mempunyai beberapa kedudukan dalam berbangsa dan bernegara. Pengamalan Pancasila di era globalisai sangat memprihatinkan. Untuk itu perlu kesadaran dari diri sendiri.Pengaruh Globalilasi sangat kuat bagi bangsa Indonesia, kita sebagai generasi penerus bangsa tidak bisa menolak arus globalisasi yang masuk ke dalam negara kita.

\section{DAFTAR PUSTAKA}

Adha, M. M., \& Susanto, E. (2020). Kekuatan Nilai-nilai Pancasila dalam Membangun Kepribadian Masyarakat Indonesia. Al-Adabiya: Jurnal Kebudayaan Dan Keagamaan, 15(01). https://doi.org/10.37680/adabiya.v15i01.319 


\section{JOURNAL OF HUMANITIES, SOCIAL SCIENCES AND BUSINESS (JHSSB) \\ VOLUME 1 ISSUE 2 (2022)}

Arum Sari Nur Hidayat, N., \& Dewi, D. A. (2021). Meningkatkan Kesadaran Generasi Muda Terhadap Implementasi Nilai-Nilai Pancasila Di Era Globalisasi. Journal of Education, Psychology, and Counseling, 3(Nomer 1).

Asmaroini, A. P. (2017). Menjaga Eksistensi Pancasila Dan Penerapannya Bagi Masyarakat Di Era Globalisasi. JPK: Jurnal Pancasila Dan Kewarganegaraan, 2(1).

Camelia. (2021, September 21). Dasar Negara Indonesia adalah Pancasila, Ketahui Makna, Fungsi, Tujuan dan Filososinya. https://www.liputan6.com/citizen6/read/4663747/dasar-negara-indonesia-adalahpancasila-ketahui-makna-fungsi-tujuan-dan-filososinya

Hadiwijono, A. (2016). Pendidikan Pancasila, Eksistensinya Bagi Mahasiswa. Jurnal Cakrawala Hukum, 7(1), 82-97. http://jurnal.unmer.ac.id/index.php/jch

Kirom, S. (2015). Mempraksiskan Pancasila Dalam Penegakan Hukum Di Indonesia. Jurnal Ilmiah CIVIS, 1 (Januari).

Nurizka, R., \& Rahim, A. (2020). Internalisasi Nilai-Nilai Pancasila dalam Membentuk Karakter Siswa Melalui Budaya Sekolah. Elementary School, 7(1).

Octavian, W. A. (2018). Urgensi Memahami dan Mengimplementasikan Nilai-Nilai Pancasila dalam Kehidupan Sehari-Hari Sebagai Sebuah Bangsa. Bhinneka Tunggal Ika, 5(2).

Putri, V. K. M., \& Gischa, S. (Edt. ). (2021, November 10). Dampak Tidak Menerapkan Sila Pancasila dalam Kehidupan Sehari-hari Artikel ini telah tayang di Kompas.com dengan judul "Dampak Tidak Menerapkan Sila Pancasila dalam Kehidupan Seharihari”, Klik untuk baca: https://www.kompas.com/skola/read/2021/11/10/150000669/dampak-tidakmenerapkan-sila-pancasila-dalam-kehidupan-sehari-hari. Kompas.Com. Vanya Karunia Mulia

Sukmalia, M., \& Dewi, D. A. (2021). Keberlangsungan dan Implementasi Nilai-Nilai Pancasila Dalam Hidup Bermasyarakat. Antropocene: Jurnal Penelitian Ilmu Humaniora, 1(2).

Suradinata, E. (2001). Pendidikan Kewarganegaraan, Jakarta, PT. Gramedia Pustaka Utama. Tamrin, A. (2017). Reposisi Strukturalisme, Semantik, Semiotik, dan Hermeneutik Pada Metodologi Tafsir Alquran Dalam Dimensi Filsafat Ilmu. SALAM: Jurnal Sosial Dan Budaya Syar-i, 4(3). https://doi.org/10.15408/sjsbs.v4i3.10300

Tilasanti, M. F., \& Dewantara, A. W. (2019). Pancasila Sebagai Pandangan Hidup Bangsa. Widodo, W. (2015). Pelaksanaan Pilkada Berdasarkan Asas Demokrasi Dan Nilai-Nilai Pancasila. Civis, 5(1).

Zulfikar, F. (2021, September 9). 9 Fungsi Pancasila sebagai Dasar Negara Indonesia Baca artikel detikedu, "9 Fungsi Pancasila sebagai Dasar Negara Indonesia" selengkapnya https://www.detik.com/edu/detikpedia/d-5716034/9-fungsi-pancasilasebagai-dasar-negara-indonesia. Download Apps Detikcom Sekarang https://apps.detik.com/detik/. DetikEdu. https://www.detik.com/edu/detikpedia/d5716034/9-fungsi-pancasila-sebagai-dasar-negara-indonesia 
Dany Try Hutama Hutabarat, Roffi Rivaldo Arya Sutta, Wahyu Habib Wardana, Zahra Nur Fadila, Prety Sapahira, Rani Tanjung 